I have thus endeavored to convey to you, in the fewest possible words, the information you desire. Permit me to add, that to this young but growing State, blessed as it is with a salubrious climate; with soil of unsurpassed richness; with an intelligent, progressive population; with a wise and efficient system of popular education; with many institutions of learning of a high grade; with rivers and railways bringing or about to bring markets to the very homes, so to say, of all the citizens; with millions of acres of fertile lands which may now be had at very low prices, but which will rapidly increase in value; with low taxes, and an unusually sound financial condition; with the privileges of religion assured to all alike; with a past prosperity hardly equaled in the country, assuring undoubted future greatness and rank among the eminent States of the Republic, we most cordially invite upright citizens of all lands and creeds to come, here in this favored land to make themselves happy homes, and help us to build up the fabric of what is surely destined to be a mighty commonwealth.

I have the honor to be, sir, your obedient servant, SAMUEL V'MERRILL, Goveqnor of Iowa.

\title{
ANNUAL MEETING OF THE IOWA STATE HISTORICAL SOCIETY.
}

Iowa City, Iowa, Tuesday Eve, Dec. 1.

The annual meeting of the State Historical Society of Iowa was held this evening in the Council Chamber; President Robt. Hutchinson, presiding. Minutes of last annual meeting read and approved.

*

Hon. B. Phillips was elected honorary member.

On motion of J. R. Hartsock, Capt. F. M.' Irish was elected life member of the Society, and not liable to the payment of the annual fees.

On motion, the Corresponding Secretary read the report of the Curators, which was received and adopted.

The Treasurer's report being read, was adopted.

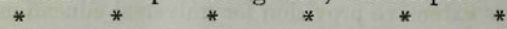


1869.] OFFIOERS OF THE STATE HISTORIOAL SOCIETY.

The Society then proceeded to the election of officers, with results as follows:

OFFICERS OF THE SOCIETY FOR THE YEAR 1869.

President-Dr. M. J. Morsman.

Vice Presidents-Rev. W. Emonds, Prof. W. G. Hammond, Rev. R. L. Ganter, Hon. Geo. G. W right, Prof. James Black and Hon. E. Clark.

Corresponding Secretary-DR. SANFORD W. HUFF. Recording Secretary - Capt. W.' Gaston.

Librarian-C. F. Clarke.

Treasurer-H. S. Welton.

CURATORS.

Hon. G. W. McCleary,

Wm. Crum,

Dr. Wm. Vogt,

Robt. Hutchinson,

Dr. H. Murray,

Hon. S. J.'Kirkwood,

M. W. Davis,

Walter Hoyt,

Hon. John P. Irish,
Hon. F. H. Lee,

A. C. Younkin,

S. E. Paine,

Thos. Hughes,

Col. H. Graham,

'Col. S. C. Trowbridge,

Rev. G. D. A. Hebard,

G. W. Dodder,

Moses Bloom.

Moved by J. P. Irish, and carried, that a committee of three be appointed to make arrangements for a lecture before the Society on the evening of the next annual election. Prof. W. G. Hammond, S. E. Paine and Rev. R. L. Ganter were appointed such committee.

*

Motion to adjourn carried.

S. E. PAINE, Rec. Sec.

President of the Board, Hon. F. H. LeE.

Report of the Board of Curators (Executive Committee) of the Ioroa State Historical Society, to the Society at its annual meeting, held December 1st, 1868, at Iowa City, Iowa.

Mr. President and Gentlemen:

Your Executive Committee elected at the last annual meeting of the Society, have the honor to submit the follow14 
ing report of the transactions of the Society which have been made through the committee during the year just past, and of its present condition:

\section{FINANCES.}

It will be remembered that at the time of the last annual meeting, the financial resources of the Society were an annuity from the State of five hundred dollars, a small sum derivable from annual dues, and from a subscription list to the ANNALs, not large and uncertain of collection, making a sum too meager to meet the positive needs of the Society, to say nothing of pushing its objects in the various channels necessary to accomplish the purpose of its organization. Pinched in its pecuniary resources, it has been constantly embarrassed in its work. Its property has suffered loss and damage for want of appropriate fixtures and rooms and care, and the duties of its official working positions were uncompensated and burdensome, as all uncompensated labor is. These considerations induced the Board to make a special effort with the legislature for an increased appropriation to meet these necessities of the Society. Hence early in the session it took measures to lay before that body, conveyed in their biennial report, and also in a memorial signed by the Board, the needs of the Society in carrying on this work. Seconded in their efforts by the representatives from this county, and also aided efficiently by the friends of the Society throughout the State, many of whom gave it kind words and recommendations to the legislature, and finally met in a spirit of friendly liberality by the members of both branches of the legislature an appropriation was made granting the full amount of the request of the friends and agents of the Society, to-wit: the liberal allowance of $\$ 3000$ annually for two years. Add to this $\$ 500$ already received, and the appropriation from the State for the current year is................ \$3500 00 Balance remaining in treasury from $1867 \ldots \ldots \ldots \quad 3500$

Total. ..................... $\overline{\$ 353500}$ Increased by the moderate amounts derived from membership and subscription to AnNals. 
DISBURSEMENTS.

The disbursements are as follows:

On orders from 1 to $31 \ldots \ldots \ldots \ldots \ldots \ldots \ldots \ldots 333039$

Incidental payments.................... $\quad 28 \quad 15$

Total....................... \$3358 54

The exact purposes for which the disbursements have been made are shown specifically in the report of the Treasurer appended, marked A 1. In general terms we may mention that the expenditures have been

1. For the rent and furnishing of a room for the reception of the property of the Society.

2. For the payment of the printing of the Ansals.

3. Compensation to the Corresponding Secretary.

4. Compensation to Librarian.

5. For procuring the necessary books of record and for cataloguing purposes, and other books and facilities for transacting the business of the Society.

For these purposes the following sums have been paid:

* * * * * * * *

ROOM.

It will be noticed that the amount paid for room fixtures is quite large. It is proper, in explanation, to call attention to the fact that at the commencement of the current year the Society was entirely houseless, occupying a room in the University, by suffrance of its trustees, and under orders to remove its property at the first practicable moment. This rendered necessary the purchase or rent of another room. The law not authorizing purchase, the Board resorted to rental, in accordance with its provisions. The Society was also comparatively destitute of appropriate furniture and proper appointments wherewith to store its valuables. To such an extent were they destitute, that a large number of books, pamphlets and papers were stacked away, in a separate basement apartment, without regard to classification or order being possible. The appropriate furniture to meet the demand has been expensive. Hence the grand total under 
this head of room and fixtures, has been swollen to a large amount for the current year. Comparatively little will be demanded for the next.

BINDING.

The binding bill is also large in consequence of the fact that papers, pamphlets and documents have been accumulating for several years. A large beginning has been made this year, and also much of the same class of expense has been postponed to the future.

\section{THE ANNALS.}

This publication has been greatly enlarged since the last volume. At that time it had not exceeded forty-eight pages. During the past year, the editor, finding encouragement for the belief that a larger number of pages could be filled with appropriate matter, has, with the consent of the Board, gradually enlarged it until it has now attained the size of one hundred pages, which is as large as it is probably judicious to make it at the present time. The subscription price remains $\$ 1.00$. The Board have duly considered the propriety of increasing the price of the subscription, and are of the opinion that for the future, if it seems feasible to continue it at the present size, to double the price of subscription. There are reasons of considerable force why this publication should not be held at the same high price as those published as individual enterprises; but that an increase of expense of publication should demand an increase of the price of the magazine, is equally obvious.

It is due further to explain, that the number of paying subscribers to the AnNaLs, while yet comparatively small, has very nearly doubled during the last year; but, like the subscriptions to all periodicals and newspapers not paid in advance, the collection is slow; but that they will all eventually be paid, is a safe expectation, in view of the character of the subscribers, most of whom are men of the highest standing in the State or in the counties and cities of their residence.

The AnNaLs is therefore not yet self-supporting in this sense, that collections cannot be made with sufficient rapidity 
to meet the immediate demands of its publication. None of the customary methods to increase its circulation have been resorted to. Nothing has been paid for advertising or agencies. Its gain in circulation is due in no degree to these, but indicate very clearly that with the effort in this direction which the Society is now able to make, a very large subscription may be procured, rendering its publication in the future entirely self-paying, and possibly remunerative to the Society.

\section{PROSPEOTIVE.}

We congratulate the members of the Society, that after the lapse of many years the Society is entering upon the dawn of a day of the realization of the specific work it was organized to accomplish; that its claims are finally being recognized the public who read its publications and the State which it was intended to aid in a work of peculiar value to its future; and that the way for the achievement of a greater usefulness is opened up than has ever before obtained.

All over the State, among the people, the State Historical Society has become a recognized institution, and its laudable objects better appreciated; its eminent citizens acknowledging its importance, and sending words of encouragement; the representatives of the people in the legislature appropriating liberally in its aid; and nothing now seems to remain but work on the part of the members of the Society, to make it all which the most sanguine of its founders contemplated, and all that such an institution is susceptible of being made; and we beg leave of the Society to suggest that there is much work of a peculiar nature to do, and do immediately. To secure the early history of the State is a prominent object of the Society. This is rapidly passing beyond the reach of this or any other depository. The men who made its history and who are capable of reprodncing it, are passing rapidly away. The animals, the birds, the fishes and the insects which inhabited its prairies, its forests, its streams and its vegetation, are passing out of sight also, and giving place to many varieties foreign to its native condition. The native human inhabitants within its 
boundaries are disappearing no less rapidly than its native brute creation. Even the flowers and plants, the trees and shrubbery indigenous to its fields and forests are giving place to exotics; and a few years hence the most indefatigable industry may be futile in gathering and classing what may then be regarded as treasures by the naturalist, or as more valuable than rubies and fine gold by the historian. This generation are the preservers of the present and the past history of the State; and of this generation the Society which is here assembled are the self-constituted agents for that preservation. To meet the responsibility resting upon it, work, active work, is necessary; without it but little can be accomplished.

We therefore beg to suggest that no member can fully meet that responsibility without giving the Society the benefit of his active influence on every proper occasion. Passivity does not meet the requirements of membership with the Society; there are active duties demanded, and whenever and wherever a word can be put in to its advantage, to encourage the work, duty demands it. Whether to secure an addition to its cabinet, a subscriber to its AnNals, a contribution to its pages, a paper for its archives, a rare book for its library, a preparation for its natural history department, a historic relic for its curiosity shelves, or a friendly word to those who can do it service, the influence or effort should be freely given.

Congratulating the Society on what has already been achieved in this important field, and trusting confidently in united efforts and ultimate abundant success, the foregoing is , Respectfully submitted.

SANFORD W. HUFF, Corresponding Secretary, For the Board of Curators. 
Copyright of Annals of Iowa is the property of State of Iowa, by \& through the State Historical Society of Iowa and its content may not be copied or emailed to multiple sites or posted to a listserv without the copyright holder's express written permission. However, users may print, download, or email articles for individual use. 